\title{
Bootstrapped DEA and Clustering Analysis of Eco-Efficiency in China's Hotel Industry
}

\author{
Yang $\mathrm{Li}^{1}{ }^{1}$, An-Chi Liu ${ }^{2} \mathbb{D}$, Yi-Ying Yu ${ }^{3}$, Yueru Zhang ${ }^{4}$, Yiting Zhan ${ }^{4}$ and Wen-Cheng Lin ${ }^{5, *(1)}$ \\ 1 Department of International Business, National Taiwan University, Taipei 10617, Taiwan; yangli@tjcu.edu.cn \\ 2 College of Business Administration, Fujian Business University, Fuzhou 350016, China; angela@fjbu.edu.cn \\ 3 Department of International Business Administration, Chinese Culture University, Taipei 11114, Taiwan; \\ g9900715@msc.pccu.edu.tw \\ 4 New Huadu Business School, Minjiang University, Fuzhou 350108, China; \\ zhangyueru_2018@nbs.edu.cn (Y.Z.); zhanyiting_2018@nbs.edu.cn (Y.Z.) \\ 5 School of Economics and Management, Guangdong University of Petrochemical Technology, \\ Maoming 525000, China \\ * Correspondence: daniel4master@gdupt.edu.cn
}

Citation: Li, Y.; Liu, A.-C.; Yu, Y.-Y.; Zhang, Y.; Zhan, Y.; Lin, W.-C. Bootstrapped DEA and Clustering Analysis of Eco-Efficiency in China's Hotel Industry. Sustainability 2022, 14 2925. https://doi.org/10.3390/ su14052925

Academic Editors: João Guerreiro and Sandra Maria Correia Loureiro

Received: 30 January 2022

Accepted: 1 March 2022

Published: 2 March 2022

Publisher's Note: MDPI stays neutral with regard to jurisdictional claims in published maps and institutional affiliations.

Copyright: (C) 2022 by the authors. Licensee MDPI, Basel, Switzerland. This article is an open access article distributed under the terms and conditions of the Creative Commons Attribution (CC BY) license (https:// creativecommons.org/licenses/by/ $4.0 /)$.

\begin{abstract}
As one of the world's largest and fastest growing industries, tourism is facing the challenge of balancing growth and eco-environmental protection. Taking tourism $\mathrm{CO}_{2}$ emissions as undesirable outputs, this research employs the bootstrapping data envelopment analysis (DEA) approach to measure the eco-efficiency of China's hotel industry. Using a dataset consisting of 31 provinces in the period 2016-2019, the bootstrapping-based test validates that the technology exhibits variable returns to scale. The partitioning around medoids (PAM) algorithm, based on the bootstrap samples of eco-efficiency, clusters China's hotel industry into two groups: Cluster 1 with Shandong as the representative medoid consists of half of the superior coastal provinces and half of the competitive inland provinces, while Cluster 2 is less efficient with Jiangsu as the representative medoid. Therefore, it is suggested that the China government conduct a survey of only Shandong and Jiangsu to approximately capture the key characteristics of the domestic hotel industry's eco-efficiency in order to formulate appropriate sustainable development policies. Lastly, biased upward eco-efficiencies may provide incorrect information and misguide managerial and/or policy implications.
\end{abstract}

Keywords: hotel industry; data envelopment analysis; eco-efficiency; returns to scale; bootstrap method; cluster analysis

\section{Introduction}

The tourism sector is one of the largest and fastest growing industries in the world. According to the Report on World Tourism Economy Trends [1], global tourism revenues were only USD 2 billion in 1950, but hit USD 5.8 trillion in 2019, which is equivalent to $6.7 \%$ of global gross domestic product (GDP). In addition to tourism revenues, global total tourist arrivals (including domestic and inbound tourist arrivals) were 25 million in 1950, but reached 12.31 billion in 2019 for an increase of $4.6 \%$ over 2018. As their demand highly correlates with the number of tourists seeking to stay overnight, hotels are one of the fastest-growing segments of the tourism sector. Furthermore, the hotel industry provides similar products and services that are visible and easily imitated by competitors; thus, it is highly competitive. Therefore, the measurement of hotel efficiency is a vital theme in tourism research.

Rapid economic development is often accompanied by considerable environmental costs such as environmental pollution. Since the 1970s, the international community has called on companies to actively practice social responsibility and promote sustainable development; for example, the United Nations recommends that companies disclose their environmental, social, and governance (ESG) practices by 2030 [2]. Sustainable 
development should meet the needs of the present without sacrificing the ability of future generations to meet their needs and also strive to achieve balanced development between human beings and nature [3]. The tourism sector contributed approximately $5 \%$ of all man-made $\mathrm{CO}_{2}$ emissions in 2005, with accommodation accounting for $21 \%$ of overall emissions, second only to transportation at $75 \%$ [4]. Thus, sustainability is clearly desirable in this important global industry.

The hotel industry can impact the environment through waste disposal such as food waste $[5,6]$, energy consumption, and water use. For instance, the International Hotel Environment Initiative [7] estimates that each guest generates an average of $0.8-1.2 \mathrm{~kg}$ of waste per day, which doubles on check-out day [8,9]. In addition, more than one-third of this waste is food waste, of which about three-quarters is still edible [10]. Given the increasing concern about ecological environment (eco-environment) issues, tourism is facing the challenge of balancing growth and ecological protection, also known as the challenge of sustainable tourism [11,12].

Since its reform and opening up in 1979, China has experienced rapid development, becoming the world's largest emerging economy and now its second largest economy. Its tourism industry has also experienced rapid growth [13]. The Golden Week holiday, which first started in 1999, has further accelerated the development of China's tourism industry [14]. With its beautiful scenery, unique culture, and rich cultural relics, China has become the world's third largest inbound tourism destination since 1990 [15] and it was the second largest tourism market in 2018 [16]. However, shortening the sector's development time has come with high environmental costs. In order to comply with the global trend of ecological environmental protection and solve its deteriorating domestic environmental problems, China has actively promoted sustainable development in recent years. Striking a balance between tourism growth and eco-environmental protection is clearly a major challenge for China.

The concept of eco-efficiency (ecological efficiency) is to create more goods and services while using fewer resources and reducing their impact on the natural environment $[17,18]$. It focuses on the practices of efficient use of resources for economic and environmental progress [19] and provides quantitative guidance for sustainable tourism growth [20,21]. In recent years, eco-efficiency has attracted more and more attention from tourism researchers [20,22], but many studies have used a partial factor framework in their assessment, ignoring the substitution relationships between factor inputs and leading to biased estimates [23]. Data envelopment analysis (DEA), as a non-parametric and total-factor analysis approach, is essentially a linear programming model that evaluates the efficiencies of decision-making units (DMUs) by calculating the best multiplier for inputs and outputs. It has been widely used in tourism eco-efficiency assessments [21,24,25].

Initially proposed by Charnes et al. [26] and called the CCR model, DEA assumes that production technology exhibits constant returns to scale (CRS). Banker et al. [27] relaxed the CRS assumption to account for variable returns to scale (VRS) and called it the BCC model. If the production technology is CRS, then both the CCR model and the BBC model will generate consistent estimators, but the latter is less efficient than the former. However, when technology exhibits VRS, then the latter still remains consistent, whereas the former becomes inconsistent [28]. Traditional DEA approaches employ linear programming techniques for solutions and thus do not directly offer clear statistical inferences.

To correctly measure the eco-efficiency of the hotel industry, this research extends the bootstrapping procedure initially proposed by Simar and Wilson [28], to statistically test the property of returns to scale for China's hotel industry by considering undesirable environmental emissions. After recognizing the appropriate returns to scale, we take a similar bootstrapping approach to obtain bias-corrected eco-efficiencies and then analyze China's hotels by location. Lastly, the bootstrapped DEA samples can help us to cluster hotels that are more similar to each other in the same group compared to those in other groups. 


\section{Literature Review}

The tourism industry consists of several different sub-sectors such as hotels, transportation, travel agencies, and so on. The market to attract tourists is highly competitive, and so the measurement of tourism efficiency is an important theme in the tourism literature. Over the past few decades, many studies have employed DEA to evaluate tourism efficiency [29-32]. Since the hotel industry is a vital sector in tourism, there is quite an extensive amount of literature on hotel efficiency [33-37]. An early study by Banker and Morey [29] measured the technical and scale efficiencies of 60 restaurants in a fast food chain, while Johns et al. [33] were the first to compare hotels using DEA. Since then, many scholars have applied DEA models to evaluate the efficiency of the hotel industry in various regions, such as the United States [38], central Europe [39], European countries [40], China [32,41], Portugal [30,42], Ecuador [43], Oman [44], Taiwan [45,46], Tunisia [31], and more.

Sustainable development must not only fulfill the needs of the present without sacrificing the ability of future generations, but must also aim to accomplish balanced development between human beings and nature [3]. In view of this, the concept of eco-efficiency offers a quantitative direction for enhancing intensive development while achieving sustainability. The simplest way to measure eco-efficiency is by taking the ratio between economic value and environmental load [47]; however, it is generally insufficient to measure eco-efficiency in a single factor framework [23]. Some studies have used composite environmental loads or adverse ecological impacts to calculate eco-efficiency indices from two or more environmental aspects [48-50], but Kuosmanen and Kortelainen [51] argued that the ecoenvironment itself cannot produce any output and must be combined with inputs such as labor and capital to produce economic output. Therefore, Reinhard et al. [52] proposed that the total-factor framework, DEA is suitable to overcome the above limitations. Since then, many scholars have chosen DEA models to assess eco-efficiency [53-58].

As tourism continues to grow globally and its adverse impact on the environment through energy consumption and pollutant emissions becomes more prominent [59], the debate on how to achieve sustainable tourism growth has become a major focus of the tourism economy literature [60]. Gossling et al. [20] first introduced the concept of ecoefficiency into the field of sustainable tourism. From then onwards, tourism eco-efficiency, which seeks to offer more tourism products and services while reducing resource consumption and pollutant emissions, has offered quantitative guidance for the sustainable growth of tourism [24]. Many research studies have assessed and analyzed tourism ecoefficiency [60-62] and eco-productivity [24,25], but to our knowledge no studies on tourism and/or the hotel industry have used a bootstrapped DEA approach for clustering studies of eco-efficiency. Hence, extending the research on eco-efficiency in tourism via an appropriate clustering study is of great significance.

\section{Methodology}

Conventional DEA approaches rely on linear programming techniques for solutions and therefore are unable to directly show any statistical inference. Thus, this study extends Simar and Wilson's [28] bootstrapping procedure to perform a hypothesis test of returns to scale by considering undesirable by-products, obtains bias-corrected eco-efficiencies, and then tests for comparisons of two means. This section provides the data to be used herein and the input-output variables.

\subsection{The Bootstrap-Based Test of Returns to Scale}

Suppose that there are $H$ decision making units (DMUs). Each DMU employs $n$ inputs $v=\left(v_{1}, \ldots, v_{n}\right) \in \Re_{+}^{n}$ to produce $m$ outputs $\boldsymbol{u}=\left(u_{1}, \ldots, u_{m}\right) \in \Re_{+}^{m}$. The CCR model proposed by Charnes et al. [26], uses the smallest free disposal convex set covering all the data to estimate the production possibility set as follows:

$$
\mathbf{\Psi}=\{(\boldsymbol{v}, \boldsymbol{u}) \mid \boldsymbol{v} \geq \mathbf{V} \boldsymbol{\lambda}, \boldsymbol{u} \leq \mathrm{U} \lambda, \lambda \geq 0\}
$$


where $\mathbf{V}=\left(\boldsymbol{v}_{1}, \ldots, \boldsymbol{v}_{H}\right), \mathbf{U}=\left(\boldsymbol{u}_{1}, \ldots, \boldsymbol{u}_{H}\right), \lambda$ is an $(N \times 1)$ vector of intensity variables, and 0 is an $(N \times 1)$ vector of zeros.

Many industries are characterized by multiple outputs, and though they may produce desirable outputs, they also generate some undesirable or unwelcome by-products. For example, the production of paper is desirable, but both biochemical oxygen and sulfur oxides are undesirable in paper and pulp mills [63]; performing loans are desirable while non-performing loans are undesirable in the banking industry [64,65]. Undesirable outputs do not show the characteristics of strong disposability, as they are only weakly disposable, and hence cannot be handled by the CCR model.

Färe and Grosskoph [66] subsequently extended the CCR model by incorporating $q$ undesirable outputs $\boldsymbol{b}=\left(b_{1}, \ldots, b_{q}\right) \in \Re_{+}^{q}$ as follows:

$$
\mathbf{\Psi}^{c r s}=\{(\boldsymbol{v}, \boldsymbol{b}, \boldsymbol{u}) \mid \boldsymbol{v} \geq \mathbf{V} \boldsymbol{\lambda}, \boldsymbol{b}=\mathbf{B} \boldsymbol{\lambda}, \boldsymbol{u} \leq \mathbf{U} \lambda, \lambda \geq 0\}
$$

where $\mathbf{B}=\left(\boldsymbol{b}_{1}, \ldots, \boldsymbol{b}_{H}\right)$. The superscript "crs" indicates that production technology exhibits constant returns to scale (CRS), which is an assumption implicit in the CCR model. The inequality constraints for desirable output vector $u$ and input vector $v$ reflect the property of strong disposability, while the equality constraint for undesirable output vector $\boldsymbol{b}$ reveals the characteristics of weak disposability. Given desirable and undesirable outputs, the input-oriented eco-efficiency of the CCR model for DMU $h, \hat{\beta}_{h}^{c r s}$, is defined as:

$$
\hat{\beta}_{h}^{c r s}=\min _{\beta, \lambda}\left\{\beta \mid\left(\beta \boldsymbol{v}_{h}, \boldsymbol{b}_{h}, \boldsymbol{u}_{h}\right) \in \mathbf{\Psi}^{\text {crs }}\right\}
$$

The CRS assumption requires that all DMUs work at optimal scale, while some DMUs may actually operate below or above optimal scale. Hence, inefficiency can arise from inappropriate scaling as well as the unsuitable mixing of inputs and outputs. The BCC model, suggested by Banker et al. [27], permits production technology to have variable returns to scale (VRS). Mathematically, we just need to add the convexity constraint $1^{\prime} \lambda=1$ in Equation (2), where $1=(1, \ldots, 1)$ is an $(N \times 1)$ vector of ones. The corresponding input-oriented eco-efficiency is:

$$
\hat{\beta}_{h}^{\text {vrs }}=\min _{\beta, \lambda}\left\{\beta \mid\left(\beta \boldsymbol{v}_{h}, \boldsymbol{b}_{h}, \boldsymbol{u}_{h}\right) \in \mathbf{\Psi}^{\text {vrs }}\right\}
$$

where

$$
\mathbf{\Psi}^{v r s}=\left\{(\boldsymbol{v}, \boldsymbol{b}, \boldsymbol{u}) \mid \boldsymbol{v} \geq \mathbf{V} \boldsymbol{\lambda}, \boldsymbol{b}=\mathbf{B} \boldsymbol{\lambda}, \boldsymbol{u} \leq \mathrm{U} \boldsymbol{\lambda}, 1^{\prime} \boldsymbol{\lambda}=1, \boldsymbol{\lambda} \geq 0\right\}
$$

The superscript "vrs" indicates that the production technology is variable returns to scale (VRS).

If the production technology exhibits CRS globally, then both $\hat{\beta}_{h}^{\text {crs }}$ and $\hat{\beta}_{h}^{\text {vrs }}$ are consistent estimators of eco-efficiency, but the former is more efficient than the latter. However, if the production technology displays VRS in some locations, then $\hat{\beta}_{h}^{\text {crs }}$ becomes inconsistent, while $\hat{\beta}_{h}^{\text {vrs }}$ remains consistent [28]. Nevertheless, conventional CCR and BCC models rely on linear programming techniques to measure eco-efficiencies and are therefore unable to directly perform any statistical inference to examine the property of returns to scale. This study extends the bootstrapping procedure of Simar and Wilson $[28,67]$ by considering undesirable environmental emissions to generate bootstrap samples, thereby testing the returns to scale. We summarize the bootstrapping procedure as follows.

(i) Use the appropriate DEA model to calculate $\hat{\rho}_{h}\left(=1 / \hat{\beta}_{h}\right)(h=1,2, \ldots, H)$.

(ii) Randomly draw a sample of size $H$ with replacement from the following set: $\left\{\left(2-\hat{\rho}_{1}\right), \ldots,\left(2-\hat{\rho}_{H}\right), \hat{\rho}_{1}, \ldots, \hat{\rho}_{H}\right\}$

to obtain $\left\{\rho_{1}^{*}, \ldots, \rho_{H}^{*}\right\}$.

(iii) Calculate $\widetilde{\rho}_{h}^{*}=\bar{\rho}^{*}+\left(\tau_{h}^{*}-\bar{\rho}^{*}\right) / \sqrt{1+\left(\gamma / \hat{\sigma}^{*}\right)^{2}}, \quad h=1, \ldots, H$, where $\tau_{h}^{*}=\rho_{h}^{*}+\gamma \varepsilon_{h}$, $\gamma=1.06 \min \{\hat{\sigma}, \hat{R} / 1.34\} H^{-1 / 5}, \hat{\sigma}$ and $\hat{R}$ are respectively the standard deviation and the interquartile range of $\left\{\hat{\rho}_{1}, \ldots, \hat{\rho}_{H}\right\}, \varepsilon_{h}$ draws randomly from a standard normal 
distribution, and $\bar{\rho}^{*}$ and $\hat{\sigma}^{*}$ are the mean and standard deviation of $\left\{\rho_{1}^{*}, \ldots, \rho_{H}^{*}\right\}$, respectively.

(iv) Calculate the bootstrap estimate $\hat{\beta}_{h}^{*}(h=1,2, \ldots, H)$ by the appropriate DEA model with technology $\left(\mathbf{V}^{*}, \mathbf{B}, \mathbf{U}\right)$, where $\mathbf{V}^{*}=\left(\boldsymbol{v}_{1}^{*}, \ldots, \boldsymbol{v}_{H}^{*}\right), \boldsymbol{v}_{h}^{*}=\widetilde{\rho}_{h}^{* *} \boldsymbol{v}_{h} / \hat{\rho}_{h}$, and $\widetilde{\rho}_{h}^{* *}=2-\widetilde{\rho}_{h}^{*}$ if $\tilde{\rho}_{h}^{*}<1$ and $\widetilde{\rho}_{h}^{* *}=\widetilde{\rho}_{h}^{*}$ otherwise.

(v) Re-do the above steps (ii) (iv) $L$ times to get bootstrap estimates $\left\{\hat{\beta}_{h l}^{*}\right\}_{h=1}^{H}$ for $l=1, \ldots, L$.

Because the assumption of CRS is more restrictive than that of VRS, we specify the null hypothesis $\mathrm{H}_{0}$ and alternative hypothesis $\mathrm{H}_{\mathrm{a}}$ as follows.

$\mathrm{H}_{0}$ : the technology set is global CRS versus $\mathrm{H}_{\mathrm{a}}$ : the technology set is VRS.

The appropriate test statistic, suggested by Simar and Wilson [67], is:

$$
T=H^{-1} \sum_{h=1}^{H} \hat{\beta}_{h}^{c r s} / \hat{\beta}_{h}^{\text {vrs }}
$$

where $\hat{\beta}_{h}^{\text {crs }} / \hat{\beta}_{h}^{\text {vrs }}$ provides an estimate of the distance between the CRS and VRS estimated frontiers in the input direction at the point where $\left(\boldsymbol{v}_{h}, \boldsymbol{b}_{h}, \boldsymbol{u}_{h}\right)$ is projected onto the estimated frontiers. By construction, $\hat{\beta}_{h}^{\text {crs }} \leq \hat{\beta}_{h}^{\text {vrs }}$, means rejecting the null hypothesis $\mathrm{H}_{0}$ if the test statistic $T$ is too small.

To perform the hypothesis test empirically, we simulate $L$ bootstrap samples of size $H$ under $\mathrm{H}_{0}$ (the production technology is global CRS). In other words, we evaluate ecoefficiencies in step (i) by the CCR model, and for each bootstrap sample $l$ we compute the bootstrap estimate $T_{l}^{*}$ to obtain the bootstrap sample $\left\{T_{l}^{*}\right\}_{l=1}^{L}$. Since we reject the null hypothesis $\mathrm{H}_{0}$ if the test statistic $T$ is small enough, the $p$-value is approximated by the proportion of bootstrap samples with values $T_{l}^{*}$ less than $t_{0}$ (the observed value of $T$ under $\mathrm{H}_{0}$ and the observed dataset):

$$
p \text {-value } \approx \sum_{l=1}^{L} \mathbf{I}\left(T_{l}^{*} \leq t_{0}\right) / L,
$$

where $\mathbf{I}(\alpha)=1$ if $\alpha$ is true and 0 otherwise.

\subsection{Correcting Eco-Efficiency Bias}

The eco-efficiency obtained by DEA, by construction, is biased upward [68]. Although it is consistent, the bias will disappear at a slow rate [69]. Let $\hat{\theta}$ be an estimator of $\theta$. The bias is defined as:

$$
\operatorname{BIAS}(\hat{\theta})=E(\hat{\theta})-\theta
$$

where $E(\hat{\theta})$ is the mathematical expectation of $\hat{\theta}$. Note that if $\hat{\theta}$ is an unbiased estimator of $\theta$, then $\operatorname{BIAS}(\hat{\theta})=0$ since $E(\hat{\theta})=\theta$.

To correct the eco-efficiency bias empirically, we first apply the bootstrap procedure, introduced in Section 3.1, for $L$ replications to obtain the bootstrap sample $\left\{\hat{\beta}_{h l}^{*}\right\}_{l=1}^{L}$ for $h=1, \ldots, H$. The bias-corrected estimator of $\hat{\beta}_{h}^{c}$ is then:

$$
\hat{\beta}_{h}^{c}=\hat{\beta}_{h}-B \hat{I A S}\left(\hat{\beta}_{h}\right)
$$

where $B \hat{I A S}\left(\hat{\beta}_{h}\right)=\overline{\hat{\beta}}_{h}^{*}-\hat{\beta}_{h}$, and $\overline{\hat{\beta}}_{h}^{*}$ is the average value of the bootstrap sample $\left\{\hat{\beta}_{h l}^{*}\right\}_{l=1}^{L}$. Nevertheless, Efron and Tibshirani [70] indicated that correcting for the bias also causes additional noise and suggested that the bias-correction should not be used unless:

$$
\left|\operatorname{BIAS}\left(\hat{\beta}_{h}\right)\right|>\operatorname{std}\left(\hat{\beta}_{h}^{*}\right) / 4
$$

where $\operatorname{std}\left(\hat{\beta}_{h}^{*}\right)=\left(L^{-1} \sum_{l=1}^{L}\left(\hat{\beta}_{h l}^{*}\right)^{2}-\left(\overline{\hat{\beta}}_{h}^{*}\right)^{2}\right)^{0.5}$. 


\subsection{The Bootstrap Test for Comparison of Two Means}

Suppose that we want to investigate whether the mean eco-efficiencies of group 1 and group 2 are equal. Null hypothesis $\mathrm{H}_{0}$ and alternative hypothesis $\mathrm{H}_{1}$ are thus specified as:

$$
\mathrm{H}_{0}: \mu_{1}=\mu_{2} \text { versus } \mathrm{H}_{1}: \mu_{1} \neq \mu_{2} \text {, }
$$

where $\mu_{1}$ and $\mu_{2}$ are the mean eco-efficiencies of group 1 and group 2, respectively. The corresponding test statistic is:

$$
\hat{\mu}=\sum_{h \in \text { group } 1} \hat{\beta}_{h} / H_{1}-\sum_{h \in \text { group } 2} \hat{\beta}_{h} / H_{2}
$$

If we have the sampling distribution of $\hat{\mu}$, then it is straightforward to construct the $100(1-2 \alpha) \%$ confidence interval for $\mu\left(=\mu_{1}-\mu_{2}\right)$. Nevertheless, we generally do not know the finite sampling distribution of $\hat{\mu}$. The bootstrap sample $\left\{\hat{\mu}_{l}^{*}\right\}_{l=1}^{L}$ provides an empirical distribution of $\left(\hat{\mu}^{*}-\hat{\mu}\right)$ and allows us to locate the values $a_{\alpha}^{*}$ and $b_{1-\alpha}^{*}$ such that:

$$
\operatorname{Pr}\left(a_{\alpha}^{*} \leq \hat{\mu}^{*}-\hat{\mu} \leq b_{1-\alpha}^{*}\right)=(1-2 \alpha)
$$

Because $(\hat{\mu}-\mu)$ approximates $\left(\hat{\mu}^{*}-\hat{\mu}\right)$, we use the bootstrap approximation:

$$
\operatorname{Pr}\left(a_{\alpha}^{*} \leq \hat{\mu}-\mu \leq b_{1-\alpha}^{*}\right) \approx(1-2 \alpha),
$$

so as to obtain the corresponding $100(1-2 \alpha) \%$ confidence interval for $\mu\left(=\mu_{1}-\mu_{2}\right)$ as:

$$
\left[\left(\hat{\mu}-b_{1-\alpha}^{*}\right),\left(\hat{\mu}-a_{\alpha}^{*}\right)\right]
$$

If the above interval does not include zero, then we reject $\mathrm{H}_{0}$ at the $200 \alpha \%$ level of significance.

\subsection{Data and Input-Output Variables}

The dataset, obtained from the Yearbook of China Tourism Statistics and the China Statistical Yearbook on the Environment, consists of 31 provinces over the period 2016-2019. Since we have 4 years of data, there are 124 observations. In addition, all nominal variables are deflated by the GDP deflator with 2017 as the base year.

The basic concept of measuring eco-efficiency is to maximize the outputs by minimizing inputs and environmental damage. Based on previous studies, we consider three desirable outputs, revenues from guest rooms, revenues from food and beverage (F\&B), and other revenues [45,71-74], and three input variables, employees, number of guest rooms, and fixed assets [71,72,74,75].

Operations in the hotel industry generate negative impacts on the environment (undesirable by-products), because it is an intensive energy user [76] and responsible for significant amounts of food waste [5,6], and so on. The carbon footprint method, which measures carbon dioxide $\left(\mathrm{CO}_{2}\right)$ emissions, is an important approach for assessing the environmental impact of tourism [77]. Following the suggestion of Gossling [78] and Qiu et al. [79], this study takes the bottom-up approach to measure $\mathrm{CO}_{2}$ emissions by using the following formula:

$$
E_{i}=365 \times \delta \times B E D_{i} \times l_{i}
$$

where $E_{i}$ is the accommodation carbon footprint in province $\mathrm{i}, B E D_{i}$ is total number of available beds in province $i, l_{i}$ is the annual average room occupancy rate in province $i$, and $\delta$ is $\mathrm{CO}_{2}$ emission per bed per night and set to be $2.458 \mathrm{~g}$. Table 1 reports the summary statistics of the inputs and outputs used herein. 
Table 1. Descriptive statistics of inputs and outputs.

\begin{tabular}{lccccc}
\hline \multicolumn{1}{c}{ Variables } & Mean & Median & Std. Dev. & Min & Max \\
\hline Inputs & & & & & \\
$\quad$ Number of employees (thousand) & 58.391 & 48.894 & 47.132 & 5.077 & 245.588 \\
$\quad$ Number of guest rooms (thousand) & 43.985 & 42.197 & 28.463 & 2.565 & 164.458 \\
$\quad$ Fixed assets (RMB billion) & 15.645 & 11.255 & 13.478 & 1.501 & 61.481 \\
\hline Undesirable Output & & & & & \\
$\quad$ CO $_{2}$ emissions (thousand tons) & 3.723 & 3.471 & 2.505 & 0.176 & 13.877 \\
\hline $\begin{array}{l}\text { Desirable Outputs } \\
\quad \text { Revenues from guest rooms (RMB billion) }\end{array}$ & 6.958 & 4.822 & 6.794 & 0.400 & 31.840 \\
$\quad$ Revenues from F\&B (RMB billion) & 4.694 & 3.215 & 4.327 & 0.197 & 18.681 \\
$\quad$ Other revenues (RMB billion) & 1.705 & 0.946 & 2.277 & 0.069 & 9.882 \\
\hline Note: All nominal variables are deflated by the GDP deflator with 2017 as the base year. & &
\end{tabular}

The output and input variables in the DEA model should satisfy the property of isotonicity - that is, increased inputs cannot reduce outputs. Table 2 presents the Pearson correlation coefficients of the input and output variables. All values are significantly positive at the $0.1 \%$ level, indicating that our selected input and output variables do indeed meet the property of isotonicity.

Table 2. Pearson correlation coefficients between input and output variables.

\begin{tabular}{ccccc}
\hline Outputs & $\begin{array}{c}\text { Revenues from } \\
\text { Guest Rooms }\end{array}$ & $\begin{array}{c}\text { Revenues from } \\
\text { F\&B }\end{array}$ & $\begin{array}{c}\text { Other } \\
\text { Revenues }\end{array}$ & $\begin{array}{c}\mathrm{CO}_{2} \\
\text { Emissions }\end{array}$ \\
\hline Number of & $\begin{array}{c}0.9265 \\
(<0.001)\end{array}$ & $\begin{array}{c}0.9537 \\
(<0.001)\end{array}$ & $\begin{array}{c}0.8271 \\
(<0.001)\end{array}$ & 0.8864 \\
$(<0.001)$
\end{tabular}

Notes: The values in parentheses are $p$-values. All correlation coefficients are significant at the $0.1 \%$ level.

\section{Results and Discussion}

This section discusses the test for returns to scale, the eco-efficiencies of China's hotel industry, coastal versus inland hotels, and the cluster analysis.

\subsection{Bootstrap-Based Test of Returns to Scale}

In any study of production efficiency, a vital question concerns whether the returns to scale of the underlying technology are increasing, constant, or decreasing. If the production technology displays CRS globally, then both $\hat{\beta}^{\text {crs }}$ and $\hat{\beta}^{\text {vrs }}$ are consistent, while the latter is less efficient than the former. This implies that we should use the CCR model to estimate eco-efficiency. On the other hand, if the production possibility set exhibits VRS at some locations, then $\hat{\beta}^{\text {vrs }}$ still remains consistent, but $\hat{\beta}^{\text {crs }}$ turns out to be inconsistent [28]. This situation suggests that the BCC model is more suitable for measuring eco-efficiency than the CCR model.

Conventional DEA models typically rely on linear programming techniques for solutions and thus cannot generally provide a formal statistical test of returns to scale. In addition, even though the DEA estimator under mild assumptions is consistent, it converges slowly and is known as the curse of dimensionality [80]. Löthgren and Tambour [81] implemented a native bootstrap method to perform statistical analyses, but unfortunately the native bootstrap method yields inconsistent estimates [82]. This study extends the bootstrap approach proposed by Simar and Wilson [28] to implement a statistical test of returns to scale by considering undesirable $\mathrm{CO}_{2}$ emissions.

This study uses R software for empirical analysis. Table 3 shows that based on 2000 replications for the bootstrapped procedure, the observed test statistic of 0.9722 is less than 
the critical value of 0.9773 for a $1 \%$ level test ( $p$-value $=0.0005)$. Therefore, we reject the null hypothesis in which the production technology is globally CRS. Hence, we apply the BCC model to estimate the eco-efficiency and analyze relevant properties of China's hotel industry.

Table 3. Bootstrap-based test of returns to scale.

\begin{tabular}{cccccc}
\hline & \multirow{2}{*}{$\boldsymbol{t}_{\boldsymbol{o}}$} & $p$-Value & \multicolumn{3}{c}{ Critical Values } \\
\cline { 4 - 5 } & & $\alpha=0.01$ & $\alpha=0.05$ & $\alpha=0.10$ \\
\hline $\begin{array}{l}\mathrm{H}_{0}: \text { CRS } \\
\mathrm{H}_{\mathrm{a}}: \text { VRS }\end{array}$ & 0.9722 & 0.0005 & 0.9773 & 0.9802 & 0.9814 \\
\hline Note: We use 2000 replications for the bootstrapped procedure. &
\end{tabular}

\subsection{General Analysis}

Eco-efficiency, by construction, is biased and asymptotically consistent at a slow rate. Following the suggestion of Simar and Wilson [67], this study applied the bootstrap procedure for 2000 replications to obtain the bootstrap sample and to correct the bias. However, Efron and Tibshirani [70] suggested that the bias-correction should not be used unless the condition of Equation (10) is satisfied. Since bootstrapping results do fulfill the condition of Equation (10) for each DMU (the mean values of $\left|B \hat{I} A S\left(\hat{\beta}_{h}\right)\right|$ and $\operatorname{std}\left(\hat{\beta}_{h}^{*}\right) / 4$ are 0.0514 and 0.0081, respectively), we shall use Equation (9) to correct the bias of ecoefficiencies.

Table 4 shows the descriptive statistics of the BCC eco-efficiency $\hat{\beta}$ and the biascorrected eco-efficiency $\hat{\beta}^{c}$. The average value of $\hat{\beta}$, obtained from Equation (4), is 0.9105 , implying on average that China's hotel industry could decrease the number of employees by about $9 \%$. Nevertheless, since eco-efficiencies are biased upward, the mean value of the bias-corrected eco-efficiency $\hat{\beta}^{c}$ at 0.8591 indicates that the hotel industry on average could potentially reduce its employees by $14 \%$ instead of $9 \%$. In addition, 35 DMUs $(28.23 \%)$ are BCC-efficient $(\hat{\beta}=1)$, or operating on the production frontier, while the maximum value of bias-corrected eco-efficiency $\hat{\beta}^{c}$ is 0.9609 , suggesting that there is no efficient DMU in our sample after correcting for bias.

Table 4. Descriptive statistics of eco-efficiencies.

\begin{tabular}{cccccc}
\hline & Mean & Median & Std. Dev. & Min & Max \\
\hline BCC Eco-Efficiency $\hat{\beta}$ & 0.9105 & 0.9134 & 0.0813 & 0.7085 & 1 \\
Bias-corrected Eco-Efficiency $\hat{\beta}^{c}$ & 0.8591 & 0.8763 & 0.0635 & 0.6776 & 0.9609
\end{tabular}

Notes: (i) We use 2000 replications for the bootstrapped procedure. (ii) Bootstrapping results do fulfill the condition of Equation (10) for each DMU, and thus we correct the bias of eco-efficiencies.

\subsection{Analysis of Coastal and Inland Hotel Industries}

Ever since the launch of economic reforms in 1978, China has advocated a progressive reform policy and shifted from a planned economy to a market economy. A series of preferential policies have shown obvious regional tendencies. The economic development of China was first concentrated in the Pearl River Delta region during the 1980s, then the Yangtze River Delta in the 1990s, and the BoHai Rim since the end of the 20th century. Hence, economic development in China is mainly concentrated in the coastal provinces (including Beijing, Tianjin, Liaoning, Hebei, Shandong, Jiangsu, Shanghai, Zhejiang, Fujian, Guangdong, Guangxi, and Hainan). As such, we might expect that the hotel industry in coastal provinces (hereafter, coastal hotels) outperform those in the inland provinces (hereafter, inland hotels). Figure 1 exhibits the provinces of the coastal and inland regions. 


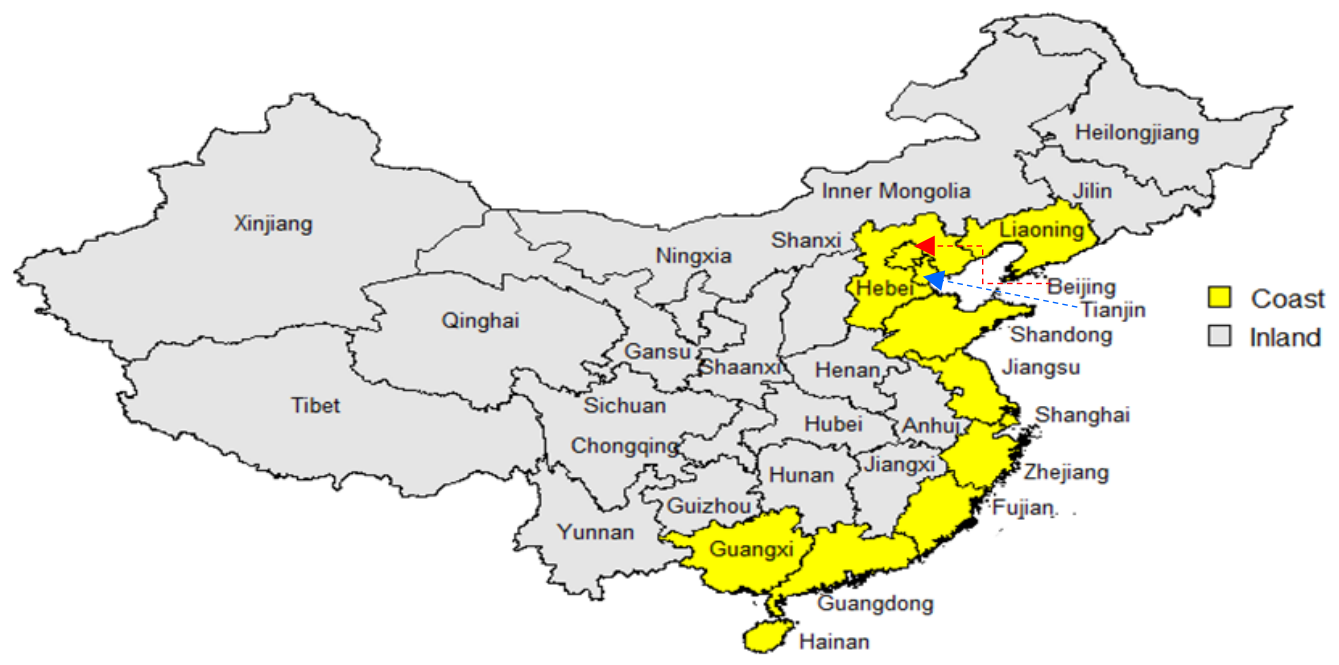

Figure 1. Provinces of the coastal and inland regions.

Table 5 shows the summary of the eco-efficiencies for the coastal and inland hotel industries. The average BCC eco-efficiency $\hat{\beta}$ of coastal hotels is 0.9293 , which is greater than that of inland hotels at 0.8986 , while the mean bias-corrected eco-efficiency $\hat{\beta}^{c}$ of coastal hotels is 0.8676 , which is only a little higher than that of inland hotels at 0.8537 . These results imply that China's hotel industry could potentially reduce the number of employees by approximately $14 \%$, regardless of location. Moreover, 35 BCC-efficient DMUs operate on the production frontier: 20 are coastal DMUs and 15 are inland DMUs.

Table 5. Summary of eco-efficiencies for the coastal and inland hotel industries.

\begin{tabular}{ccccccc}
\hline & Mean & Median & Std. Dev. & Min & Max & $\begin{array}{c}\text { No. of Provinces } \\
\text { (DMUs) }\end{array}$ \\
\hline \multicolumn{7}{c}{ BCC Eco-Efficiency $\hat{\beta}$} \\
\hline Overall & 0.9105 & 0.9134 & 0.0813 & 0.7085 & 1 & $31(124)$ \\
\hline Coastal Hotels & 0.9293 & 0.9542 & 0.0798 & 0.7583 & 1 & $12(48)$ \\
Inland Hotels & 0.8986 & 0.8968 & 0.0804 & 0.7085 & 1 & $19(76)$ \\
\hline & & \multicolumn{7}{c}{ Bias-corrected Eco-Efficiency $\hat{\beta}^{c}$} & & \\
\hline Overall & 0.8591 & 0.8763 & 0.0635 & 0.6776 & 0.9609 & $31(124)$ \\
\hline Coastal Hotels & 0.8676 & 0.8831 & 0.0596 & 0.7322 & 0.9588 & $12(48)$ \\
Inland Hotels & 0.8537 & 0.8652 & 0.0657 & 0.6776 & 0.9609 & $19(76)$ \\
\hline
\end{tabular}

Although the average eco-efficiencies of the hotel industry reveal discrepancies among different locations, we need additional analysis to examine whether they are significantly different. Some research studies have used analysis of variance (ANOVA) to investigate whether the mean eco-efficiencies among groups are equal $[65,83,84]$. However, ANOVA assumes that all populations are normal and have equal variances. Some studies have applied the non-parametric test [85], which depends on the properties of large samples [86]. Daraio and Simar [69] pointed out that even though BCC eco-efficiency estimators are asymptotically consistent, they converge very slowly.

We employed the bootstrap procedure for 2000 replicates to acquire bootstrap samples and to construct confidence intervals for the mean eco-efficiency differences between coastal and inland hotels. Table 6 indicates that the $90 \%$ and $95 \%$ confidence intervals do contain zero values. Hence, we conclude that the mean eco-efficiencies between coastal and inland hotels do not reveal significant differences at the $10 \%$ level $(p$-value $=0.24)$. Note that the $p$-values of the non-parametric test (whether mean eco-efficiencies between coastal and inland hotels are equal) for BCC eco-efficiency is 0.0248 - that is, coastal hotels statistically 
outperform inland hotels at the $5 \%$ level of significance. This suggests that biased upward eco-efficiencies may deliver incorrect information and misguide managerial and/or policy implications.

Table 6. The bootstrap test for coastal versus inland hotels.

\begin{tabular}{|c|c|c|c|c|c|}
\hline & \multicolumn{2}{|c|}{ Mean Eco-Efficiency } & \multicolumn{2}{|c|}{ The $100(1-2 \alpha) \%$ Confidence Intervals } & \multirow[b]{2}{*}{$p$-Value } \\
\hline & $\hat{\beta}$ & $\hat{\beta}^{c}$ & $\alpha=0.025$ & $\alpha=0.05$ & \\
\hline $\begin{array}{l}\text { Coastal Hotels } \\
\text { Inland Hotels }\end{array}$ & $\begin{array}{l}0.9293 \\
0.8986\end{array}$ & $\begin{array}{l}0.8676 \\
0.8537\end{array}$ & {$[-0.0085,0.0343]$} & {$[-0.0050,0.0324]$} & 0.24 \\
\hline
\end{tabular}

Notes: (1) We use 2000 replications for the bootstrapped procedure. (2) The $p$-values of the non-parametric test for the BCC eco-efficiency is 0.0248 .

\subsection{Cluster Analysis}

We have so far investigated the eco-efficiency of the hotel industry by coastal and inland regions, but this is unlikely to fully characterize China's hotel industry. Cluster analysis is a multivariate method that aims to classify similar objects (such as regions, provinces, companies, and so on) in the same group based on a set of variables. It involves a large number of techniques, methods, and algorithms that can be applied in various fields, including banking, marketing, tourism, etc. Several studies have used it to complement DEA studies [87-89].

The $k$-medoids or partitioning around medoids (PAM) algorithm is a clustering approach used to map a distance matrix into $k$ clusters. It is like the $k$-means algorithm, but is based on the search for $k$ representative objects, or medoids, among the objects in the dataset [90]. It is also more robust to noise and outliers as compared to $k$-means since it minimizes a sum of general pairwise dissimilarities instead of a sum of squared Euclidean distances. Furthermore, the medoids are robust representations of the cluster centers, whereas the cluster center in $k$-means is not necessarily one of the objects (it is the average between the objects in the cluster).

The bootstrap samples of eco-efficiency can help us to construct a distance matrix based on the probability that the order of two objects may be reversed [89,91]. Let $\bar{\beta}_{h}$ be the mean eco-efficiency of the $h$ th object over the sample periods. If the $j$ th object completely outperforms the $h$ th object, then $\operatorname{Pr}\left(\bar{\beta}_{h}-\bar{\beta}_{j}>0\right)=0$. Contrarily, if the $h$ th object completely outperforms the $j$ th object, then $\operatorname{Pr}\left(\bar{\beta}_{h}-\bar{\beta}_{j}>0\right)=1$. Both cases reveal the largest dissimilarity between the $h$ th object and the $j$ th object, that is, both objects never switch in rank over all of the bootstrap samples.

In contrast to those two extreme cases, $\operatorname{Pr}\left(\bar{\beta}_{h}-\bar{\beta}_{j}>0\right)=0.5$ discloses the smallest dissimilarity between the $h$ th object and the $j$ th object. In other words, both objects have an equal likelihood of outperforming each other. Hence, we measure the distance between the $h$ th object and the $j$ th object by:

$$
D_{p}(h, j)=\left|\operatorname{Pr}\left(\bar{\beta}_{h}-\bar{\beta}_{j}>0\right)-0.5\right| \times 200
$$

The values of $D_{p}(h, j)$ are between 0 and 100 . Higher values of $D_{p}(h, j)$ imply a larger dissimilarity between the $h$ th object and the jth object. Given the bootstrap samples of the eco-efficiency, we use the distance metric $D_{p}(h, j)$ to compute the (symmetric) dissimilarity matrix. The $k$-medoids clustering minimizes the average dissimilarity of objects to their closest representative object (medoid).

We applied the "cluster" package in $\mathrm{R}$ software to map a distance matrix into $k$ clusters. Figure $2 \mathrm{a}, \mathrm{b}$ are bivariate cluster plots for $k=2$ and $k=3$, respectively. All 31 objects are standardized and represented by points in the plot, using the first two principal components. An ellipse is drawn around each cluster. Figure $2 \mathrm{~b}$ shows that there are considerable observations in the overlapping area of Cluster 1 and Cluster 2. Hence, we chose $k=2$ for the cluster analysis of China's hotel industry. 


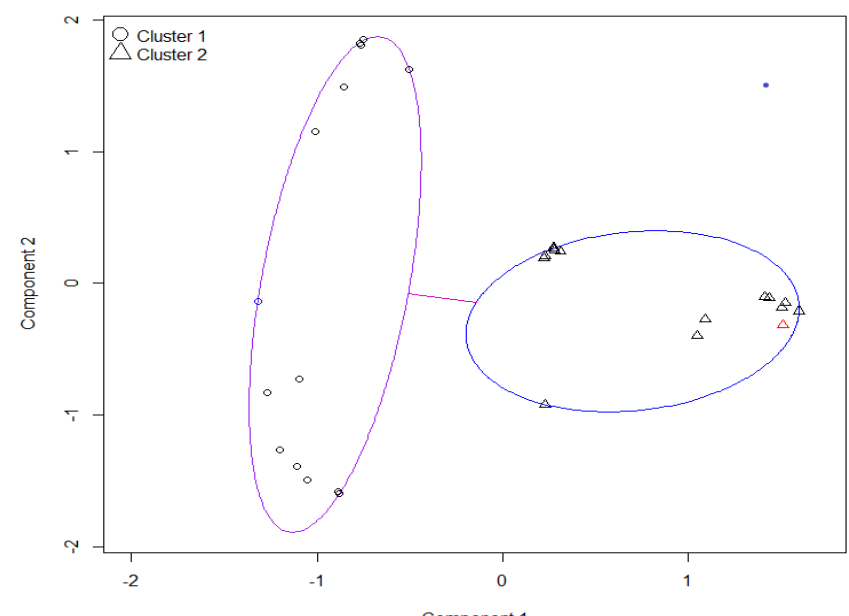

(a)

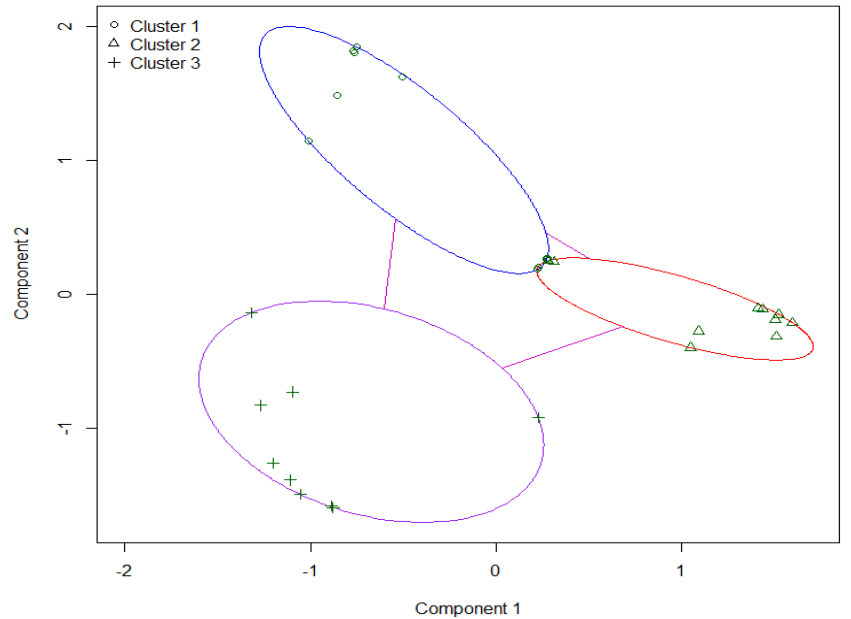

(b)

Figure 2. Bivariate cluster plots of partitioning around medoids. (a) Bivariate Cluster Plot of PAM for $k=2$; (b) Bivariate Cluster Plot of PAM for $k=3$.

Table 7 indicates that Cluster 1 has higher mean values for both eco-efficiencies $\hat{\beta}$ and $\hat{\beta}^{c}(0.9738$ and 0.9018$)$ than Cluster 2 (0.8583 and 0.8239). In addition, Cluster 1 contains all the efficient provinces of the BCC model, while the corresponding maximum eco-efficiency in Cluster 2 is 0.9307 . In Cluster 1, the coastal and inland provinces are evenly divided. Hence, we can characterize the samples of Cluster 1 as half being superior coastal provinces and half of those competitive provinces being located in the inland region, while Cluster 2 is less efficient than Cluster 1 and mainly covers inland provinces.

Table 7. Results of partitioning around medoids for $K=2$.

\begin{tabular}{|c|c|c|c|c|}
\hline & \multicolumn{2}{|c|}{ Cluster 1} & \multicolumn{2}{|c|}{ Cluster 2} \\
\hline & $\hat{\beta}$ & $\hat{\beta}^{c}$ & $\hat{\beta}$ & $\hat{\beta}^{c}$ \\
\hline Mean & 0.9738 & 0.9018 & 0.8583 & 0.8239 \\
\hline Median & 0.9707 & 0.9016 & 0.8803 & 0.8377 \\
\hline Std. Dev. & 0.0227 & 0.0192 & 0.0513 & 0.0482 \\
\hline Min & 0.9374 & 0.8698 & 0.7775 & 0.7407 \\
\hline $\operatorname{Max}$ & 1 & 0.9279 & 0.9307 & 0.9137 \\
\hline Representative & \multicolumn{2}{|c|}{ Shandong } & \multicolumn{2}{|c|}{ Jiangsu } \\
\hline Province & 0.9664 & 0.8944 & 0.8899 & 0.8514 \\
\hline Number of Provinces & \multicolumn{2}{|c|}{14} & \multicolumn{2}{|c|}{17} \\
\hline Coastal Provinces & \multicolumn{2}{|c|}{7} & \multicolumn{2}{|c|}{5} \\
\hline Inland Provinces & \multicolumn{2}{|c|}{7} & \multicolumn{2}{|c|}{12} \\
\hline
\end{tabular}

One useful clustering application is to characterize the clusters by means of typical or representative objects. The $k$-medoids algorithm is based on the search for $k$ representative medoids with a dataset whose average dissimilarity to all the objects in the cluster is minimal. A medoid is not only the representative object of a cluster and the most centrally located point in that cluster, but it is also actually an observation and can be used economically or conveniently to represent that cluster. In other words, these medoids provide a characterization of the clusters and also offer a chance for investigation by using only a small set of $k$ medoids instead of a large set to start off with. Table 7 shows that the representative medoids for Cluster 1 and Cluster 2 are Shandong and Jiangsu, respectively. Hence, we are able to conveniently analyze these two provinces so as to properly capture the main features of the eco-efficiency of China's hotel industry. Figure 3 displays the provinces in Cluster 1 and Cluster 2. 


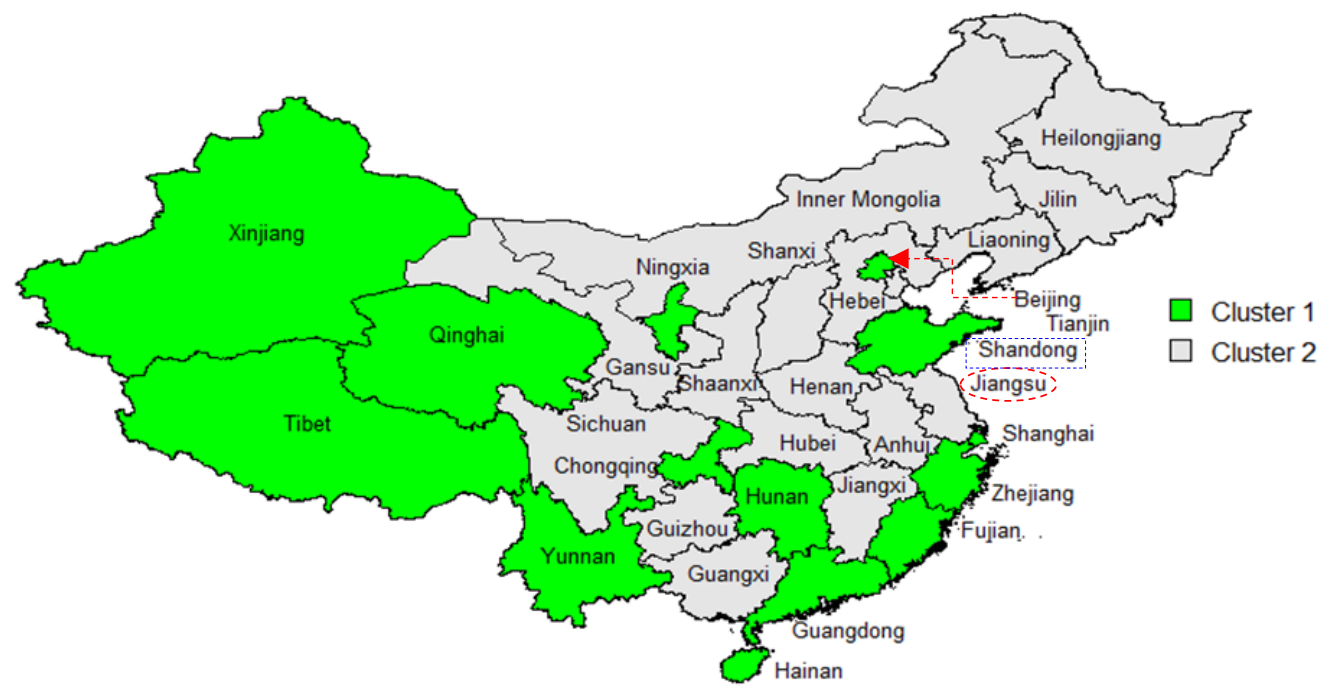

Figure 3. Provinces in Cluster 1 and Cluster 2.

The empirical results show that the mean eco-efficiencies do not reveal significant differences between coastal and inland hotels, which may suggest that governments can simply plan or execute national policies to promote the sustainable development of the hotel industry, regardless of regional and/or economic development. However, cluster analysis indicates that the eco-efficiency of China's hotel industry presents considerable differences, and is divided into at least two clusters. Therefore, the central government should formulate or implement eco-environmental policies according to the degree of eco-efficiency in order to effectively promote the sustainable development of its domestic hotel industry.

\section{Conclusions}

Global climate change, which is mainly characterized by climate warming, has increasingly become a serious challenge for mankind. Tourism is one of the world's largest and fastest growing industries, and its eco-environmental issues have increasingly attracted widespread attention from governments and the international community. Hence, the tourism industry is facing the challenge of balancing growth and eco-environmental protection. Taking tourism $\mathrm{CO}_{2}$ emissions as undesired outputs, this study utilized the bootstrapping procedure to measure the eco-efficiency of China's hotel industry. After identifying appropriate returns to scale by using the bootstrapping-based test, we applied a similar bootstrapping approach to correct for biases in eco-efficiency and to perform cluster analysis.

The dataset consists of 31 provinces over the period 2016-2019, thus covering 124 observations. The test for returns to scale does support the research hypothesis that production technology exhibits VRS. Furthermore, biased upward eco-efficiencies may provide incorrect information and misguide managerial and/or policy implications. The $k$-medoids clustering, based on the bootstrap samples of eco-efficiency, partitions China's hotel industry into two clusters: Cluster 1 contains half of the better coastal provinces and half of those competitive provinces in the inland region, whereas Cluster 2 is less efficient than Cluster 1 , covering about two-thirds of the inland provinces. In addition, the representative medoids of Cluster 1 and Cluster 2 are Shandong and Jiangsu, respectively.

One limitation of this study is the use of the carbon footprint method to measure $\mathrm{CO}_{2}$ emissions as an undesirable by-product of the hotel industry. The operational impacts of this industry on the ecological environment consist of diverse components such as energy consumption, water use, and waste disposal. They may have distinct impacts on the environment, but a single index assumes that their effects are homogeneous. Future studies could construct a multi-indicator framework to measure the undesirable by-products 
of the hotel industry so as to comprehensively evaluate its eco-efficiency. In addition, future research could also apply conditional non-parametric frontier methods to analyze how external environmental variables that are neither inputs, nor desirable outputs, nor undesirable by-products affect tourism eco-efficiency.

Author Contributions: Conceptualization, Y.L. and A.-C.L.; methodology, Y.L.; software, Y.L.; validation, Y.L., Y.Z. (Yueru Zhang) and Y.Z. (Yiting Zhan); formal analysis, Y.L., A.-C.L., Y.-Y.Y. and W.-C.L.; investigation, Y.Z. (Yueru Zhang) and Y.Z. (Yiting Zhan); resources, W.-C.L.; data curation, W.-C.L.; writing—original draft preparation, Y.L., A.-C.L., Y.-Y.Y. and W.-C.L.; writing—review and editing, Y.L., A.-C.L. and Y.-Y.Y.; visualization, Y.Z. (Yueru Zhang) and Y.Z. (Yiting Zhan); supervision, Y.L. and Y.-Y.Y.; project administration, Y.-Y.Y. and W.-C.L.; funding acquisition, W.-C.L. All authors have read and agreed to the published version of the manuscript.

Funding: This research received no external funding.

Institutional Review Board Statement: Not applicable.

Informed Consent Statement: Not applicable.

Data Availability Statement: The data presented in this study are available upon request from the corresponding author.

Conflicts of Interest: The authors declare no conflict of interest.

\section{References}

1. Report on World Tourism Economy Trends. 2020. Available online: https://cn.wtcf.org.cn/special/2020/0110/4988.html (accessed on 26 January 2022).

2. Sustainable Stock Exchanges. Sustainable Stock Exchanges Initiative: Model Guidance on Reporting ESG Information to Investors. 2015. Available online: www.sseinitiative.org/wp-content/uploads/2015/09/SSE-Model-Guidance-on-Reporting-ESG.pdf (accessed on 29 February 2020).

3. World Commission on Environment and Development. Our Common Future; Oxford University Press: Oxford, UK, 1987.

4. World Tourism Organization; International Transport Forum. Transport-Related $\mathrm{CO}_{2}$ Emissions of the Tourism Sector-Modelling Results; UNWTO: Madrid, Spain, 2019. [CrossRef]

5. Malefors, C.; Callewaert, P.; Hansson, P.A.; Hartikainen, H.; Pietilainen, O.; Strid, I.; Strotmann, C.; Eriksson, M. Towards a baseline for Food-Waste quantification in the hospitality Sector-Quantities and data processing criteria. Sustainability 2019, 11,3541. [CrossRef]

6. Amicarelli, V.; Aluculusei, A.C.; Lagioia, G.; Pamfilie, R.; Bux, C. How to manage and minimize food waste in the hotel industry? An exploratory research. Int. J. Cult. Tour. Hosp. Res. 2021. [CrossRef]

7. International Hotel Environmental Initiative. Hotels Case: Community Action and Responsibility for the Environment; IHEI: London, UK, 2002.

8. Pirani, S.I.; Arafat, H. Solid waste management in the hospitality industry: A review. J. Environ. Manag. 2014, 146, 320-336. [CrossRef] [PubMed]

9. Abdulredha, M.; Al Khaddar, R.; Jordan, D.; Kot, P.; Abdulridha, A.; Hashim, K. Estimating solid waste generation by hospitality industry during major festivals: A quantification model based on multiple regression. Waste Manag. 2018, 77, 388-400. [CrossRef] [PubMed]

10. Williams, P.; Leach, B.; Christensen, K.; Armstron, G.D.; Hawkins, R.P.; Lane, A.J.G.; Scholes, P. The Composition of Waste Disposed of by the UK Hospitality Industry; Report RES093-001; Waste \& Resources Action Programme (WRAP): Banbury, UK, 2011.

11. Hall, C.M. Framing behavioural approaches to understanding and governing sustainable tourism consumption: Beyond neoliberalism, "nudging" and "green growth"? J. Sustain. Tour. 2013, 21, 1091-1109. [CrossRef]

12. Bella, G. Estimating the tourism induced environmental Kuznets curve in France. J. Sustain. Tour. 2018, 26, 2043-2052. [CrossRef]

13. Yang, Y.; Liu, Z.-H.; Qi, Q. Domestic tourism demand of urban and rural residents in China: Does relative income matter? Tour. Manag. 2014, 40, 193-202. [CrossRef]

14. York, Q.Y.; Zhang, H.Q. The determinants of the 1999 and 2007 chinese golden holiday system: A content analysis of official documentation. Tour. Manag. 2010, 31, 881-890. [CrossRef]

15. Deng, T.; Li, X.; Ma, M. Evaluating impact of air pollution on China's inbound tourism industry: A spatial econometric approach. Asia Pac. J. Tour. Res. 2017, 2, 771-780. [CrossRef]

16. World Travel and Tourism Council. Economic Impact Reports. 2019. Available online: https:/ /www.wttc.org/economic-impact/ country-analysis/ (accessed on 14 October 2020).

17. Verfaillie, H.A.; Bidwell, R. Measuring Eco-Efficiency. In A Guide to Reporting Company Performance; World Business Council for Sustainable Development: Geneva, Switzerland, 2000. 
18. Amicarelli, V.; Rana, L.R.; Lombardi, M.; Bux, C. Material flow analysis and sustainability of the Italian meat industry. J. Clean. Prod. 2021, 299, 126902. [CrossRef]

19. United Nations. Eco-Efficiency Indicators: Measuring Resource-Use Efficiency and the Impact of Economic Activities on the Environment; ST/ESCAP/2561; United Nations Publication: Bangkok, Thailand, 2009.

20. Gossling, S.; Peeters, P.; Ceron, J.P.; Dubois, G.; Patterson, T.; Richardson, R.B. The eco-efficiency of tourism. Ecol. Econ. 2005, 54, 417-434. [CrossRef]

21. Zha, J.; Yuan, W.; Dai, J.; Tan, T.; He, L. Eco-efficiency, eco-productivity and tourism growth in China: A non-convex metafrontier DEA-based decomposition model. J. Sustain. Tour. 2020, 28, 663-685. [CrossRef]

22. Hadjikakou, M.; Miller, G.; Chenoweth, J.; Druckman, A.; Zoumides, C. A comprehensive framework for comparing water use intensity across different tourist types. J. Sustain. Tour. 2015, 23, 1445-1467. [CrossRef]

23. Huang, J.; Yang, X.; Cheng, G.; Wang, S. A comprehensive eco-efficiency model and dynamics of regional eco-efficiency in China. J. Clean. Prod. 2014, 67, 228-238. [CrossRef]

24. Liu, J.; Zhang, J.; Fu, Z. Tourism eco-efficiency of Chinese coastal cities-analysis based on the DEA-Tobit model. Ocean. Coast Manag. 2017, 148, 164-170. [CrossRef]

25. Peng, H.; Zhang, J.; Lu, L.; Tang, G.; Yan, B.; Xiao, X.; Han, Y. Eco-efficiency and its determinants at a tourism destination: A case study of Huangshan National Park, China. Tour. Manag. 2017, 60, 201-211. [CrossRef]

26. Charnes, A.; Cooper, W.W.; Rhodes, E. Measuring the Efficiency of Decision-making Units. Eur. J. Oper. Res. 1978, 2, $429-444$. [CrossRef]

27. Banker, R.D.; Charnres, A.; Cooper, W.W. Some Models for Estimation of Technical and Scale Inefficiencies in Data Envelopment Analysis. Manag. Sci. 1984, 30, 1078-1092. [CrossRef]

28. Simar, L.; Wilson, P.W. Non-Parametric Tests of Returns to Scale. Eur. J. Oper. Res. 2002, 139, 115-132. [CrossRef]

29. Banker, R.D.; Morey, R.C. Efficiency analysis for exogenously fixed inputs and outputs. Oper. Res. 1986, 34, 513-521. [CrossRef]

30. Barros, C.P.; Mascarenhas, M.J. Technical and allocative efficiency in a chain of small hotels. Int. J. Hosp. Manag. 2005, 24, 415-436. [CrossRef]

31. Hathroubi, S.; Peypoch, N.; Robinot, E. Technical efficiency and environmental management: The Tunisian case. J. Hosp. Tour. Manag. 2014, 21, 27-33. [CrossRef]

32. Xia, B.; Dong, S.; Zhao, M.; Li, Z.; Li, F.; Li, Y.; Cheng, H. Analysis of economic efficiency and eco-efficiency of Chinese star hotels based on SBM model. Earth Environ. Sci. 2018, 190, 12066. [CrossRef]

33. Johns, N.; Howcroft, B.; Drake, L. The use of data envelopment analysis to monitor hotel productivity. Prog. Tour. Hosp. Res. 1997, 3, 119-127. [CrossRef]

34. Assaf, A.; Barros, C.P. Performance analysis of the Gulf hotel industry: A Malmquist index with bias correction. Int. J. Hosp. Manag. 2011, 30, 819-826. [CrossRef]

35. Assaf, A.; Cvelbar, L.K.; Pahor, M. Performance drivers in the casino industry: Evidence from Slovenia. Int. J. Hosp. Manag. 2012, 32, 149-154. [CrossRef]

36. Mendieta-Peñalver, L.F.; Perles-Ribes, J.F.; Ramón-Rodríguez, A.B.; Such-Devesa, M.J. Is hotel efficiency necessary for tourism destination competitiveness? An integrated approach. Tour. Econ. 2018, 24, 3-26. [CrossRef]

37. Lado-Sestayo, R.; Fernández-Castro, Á.S. The impact of tourist destination on hotel efficiency: A data envelopment analysis approach. Eur. J. Oper. Res. 2019, 272, 674-686. [CrossRef]

38. Anderson, R.I.; Fok, R.; Scott, J. Hotel Industry Efficiency: An Advanced Linear Programming Examination. Am. Bus. Rev. 2000, $18,40-48$

39. Ilić, I.; Petrevska, I. Using DEA method for determining tourism efficiency of Serbia and the surrounding countries. Hotel. Tour. Manag. 2018, 6, 73-80. [CrossRef]

40. Soysal-Kurt, H. Measuring Tourism Efficiency of European Countries by Using Data Envelopment Analysis. Eur. Sci. J. 2017, 13, 1857-7881. [CrossRef]

41. Sun, Y.; Hou, G.; Huang, Z.; Zhong, Y. Spatial-Temporal Differences and Influencing Factors of Tourism Eco-Efficiency in China's Three Major Urban Agglomerations Based on the Super-EBM Model. Sustainability 2020, 12, 4156. [CrossRef]

42. Barros, C.P.; Alves, F.P. Productivity in tourism industry. Int. Adv. Econ. Res. 2004, 10, 215-225. [CrossRef]

43. Higuerey, A.; Viñan-Merecí, C.; Malo-Montoya, Z.; Martínez-Fernández, V. Data Envelopment Analysis (DEA) for Measuring the Efficiency of the Hotel Industry in Ecuador. Sustainability 2020, 12, 1590. [CrossRef]

44. Oukil, A.; Channouf, N.; Al-Zaidi, A. Performance evaluation of the hotel industry in an emerging tourism destination: The case of Oman. J. Hosp. Tour. Manag. 2016, 29, 60-68. [CrossRef]

45. Lee, Y.L.; Kuo, S.H.; Jiang, M.Y.; Li, Y. Evaluating the performances of Taiwan's international tourist hotels: Applying the directional distance function and meta-frontier approach. Sustainability 2019, 11, 5773. [CrossRef]

46. Yin, P.; Chu, J.; Wu, J.; Ding, J.; Yang, M.; Wang, Y. A DEA-based two-stage network approach for hotel performance analysis: An internal cooperation perspective. Omega 2020, 93, 102035. [CrossRef]

47. Zhang, B.; Bi, J.; Fan, Z.; Yuan, Z.; Ge, J. Eco-efficiency analysis of industrial system in China: A data envelopment analysis approach. Ecol. Econ. 2008, 68, 306-316. [CrossRef]

48. Mickwitz, P.; Melanen, M.; Rosenstrom, U.; Seppala, J. Regional eco-efficiency indicators—A participatory approach. J. Clean. Prod. 2006, 14, 1603-1611. [CrossRef] 
49. Ji, D. Evaluation on China's regional eco-efficiency: Based on ecological footprint methodology. Contemp. Econ. Manag. 2013, 35, $57-62$.

50. Wang, J. A comprehensive evaluation of China's provincial ecological pressure and ecological efficiency: Based on ecological footprint method. J. Contemp. Financ. Econ. 2016, 8, 3-15.

51. Kuosmanen, T.; Kortelainen, M. Measuring eco-efficiency of production with data envelopment analysis. J. Ind. Ecol 2005, 9 59-72. [CrossRef]

52. Reinhard, S.; Lovell, C.A.K.; Thijssen, G.J. Environmental efficiency with multiple environmentally detrimental variables; estimated with SFA and DEA. Eur. J. Oper. Res. 2000, 121, 287-303. [CrossRef]

53. Mahlberg, B.; Luptacik, M. Eco-efficiency and eco-productivity change over time in a multisectoral economic system. Eur. J. Oper. Res. 2014, 234, 885-897. [CrossRef]

54. Lampe, H.W.; Hilgers, D. Trajectories of efficiency measurement: A bibliometric analysis of DEA and SFA. Eur. J. Oper. Res. 2015, 240, 1-21. [CrossRef]

55. Woo, C.; Chung, Y.; Chun, D.; Seo, H.; Hong, S. The static and dynamic environmental efficiency of renewable energy: A Malmquist index analysis of OECD countries. Renew. Sust. Energy Rev. 2015, 47, 367-376. [CrossRef]

56. Broadstock, D.C.; Li, J.; Zhang, D. Efficiency snakes and energy ladders: A (meta-) frontier demand analysis of electricity consumption efficiency in Chinese households. Energy Policy 2016, 91, 383-396. [CrossRef]

57. Yu, Y.; Huang, J.; Zhang, N. Industrial eco-efficiency, regional disparity, and spatial convergence of China's regions. J. Clean. Prod. 2018, 204, 872-887. [CrossRef]

58. Chen, L.; Huang, Y.; Li, M.J.; Wang, Y.M. Meta-frontier analysis using cross-efficiency method for performance evaluation. Eur. J. Oper. Res. 2020, 280, 219-229. [CrossRef]

59. Sofield, T.; Li, S. Tourism governance and sustainable national development in China: A macro-level synthesis. J. Sustain. Tour. 2011, 19, 501-534. [CrossRef]

60. Han, J. Carrying capacity of low carbon tourism environment in coastal areas from the perspective of ecological efficiency. J. Coast. Res. 2018, 83, 199-203. [CrossRef]

61. Yang, G.H.; Li, P.; Zheng, B.A.; Zhang, Y.Q. GHG emission-based eco-efficiency study on tourism itinerary products in Shangri-La, Yunnan Province, China. Curr. Issues Tour. 2008, 11, 604-622. [CrossRef]

62. Rungsrisawat, S. Image of tourism destinations-principles of macromarketing and environmental efficiency: The case of Thailand. Int. J. Ecol. Dev. 2017, 32, 133-140.

63. Färe, R.; Grosskopf, S.; Lovell, C.K.; Yaisawarng, S. Derivation of Shadow Prices for Undesirable Outputs: A Distance Function Approach. Rev. Econ. Statis. 1993, 75, 374-380. [CrossRef]

64. Chang, C.-C. The Nonparametric Risk-Adjusted Efficiency Measurement: An Application to Taiwan's Major Rural Financial Intermediaries. Am. J. Agric. Econ. 1999, 81, 902-913. [CrossRef]

65. Li, Y.; Hu, J.L.; Liu, H.W. Non-performing Loans and Bank Efficiencies: An Application of the Input Distance Function Approach. J. Stat. Manag. Syst. 2009, 12, 435-450. [CrossRef]

66. Färe, R.; Grosskopf, S. New Directions: Efficiency and Productivity; Springer: New York, NY, USA, 2004.

67. Simar, L.; Wilson, P.W. Sensitivity Analysis of Efficiency Scores: How to Bootstrap in Nonparametric Frontier Models. Manag. Sci. 1998, 44, 49-61. [CrossRef]

68. Banker, R.D. Maximum Likelihood, Consistency and Data Envelopment Analysis: A Statistical Foundation. Manag. Sci. 1993, 39, 1265-1273. [CrossRef]

69. Daraio, C.; Simar, L. Advanced Robust and Nonparametric Methods in Efficiency Analysis: Methodology and Applications; Springer: New York, NY, USA, 2007.

70. Efron, B.; Tibshirani, R.J. An Introduction to the Bootstrap; Chapman and Hall: New York, NY, USA, 1993.

71. Wang, F.C.; Hung, W.T.; Shang, J.K. Measuring Pure Managerial Efficiency of International Tourist Hotels in Taiwan. Serv. Ind. J. 2006, 26, 59-71. [CrossRef]

72. Shyu, J.; Hung, S.C. The True Managerial Efficiency of International Tourist Hotels in Taiwan: Three-stage Data Envelopment Analysis. Serv. Ind. J. 2012, 32, 1991-2004. [CrossRef]

73. Chen, C.M.; Chang, K.L.; Langelett, G. How Demand Uncertainty and Market Concentration Affect Long-term Price Instability. Int. J. Hosp. Manag. 2014, 37, 146-149. [CrossRef]

74. Guo, X.; Wei, W.; Li, Y.; Wang, L.Y. A Study of Different Types of Air Pollutants on the Efficiency of China's Hotel Industry. Int. J. Environ. Res 2019, 16, 4319. [CrossRef]

75. Shieh, H.S.; Hu, J.L.; Gao, L.Y. Tourist Preferences and Cost Efficiency of International Tourist Hotels in Taiwan. Int. J. Mark. Stud. 2014, 6, 1918-7203. [CrossRef]

76. World Tourism Organization; United Nations Environment Programme. Climate Change and Tourism: Responding to Global challenges; World Tourism Organization: Madrid, Spain, 2008.

77. Dong, X.; Zhang, J.; Zhang, J.; Cheng, S. A Critical review on several issues of regional tourism-related carbon emissions or its carbon footprint. Acta Ecol. Sin. 2016, 36, 554-568.

78. Gossling, S. Global environmental consequences of tourism. Glob. Environ. Chang. 2002, 12, 283-302. [CrossRef]

79. Qiu, X.; Fang, Y.; Yang, X.; Zhu, F. Tourism Eco-Efficiency Measurement, Characteristics, and Its Influence Factors in China. Sustainability 2017, 9, 1634. [CrossRef] 
80. Kneip, A.; Simar, L.; Wilson, P.W. Asymptotics for DEA Estimators in Non-Parametric Frontier Models; Discussion Paper No. 0317; Institut de Statistique, Universite' Catholique de Louvain: Louvain-la-Neuve, Belgium, 2003.

81. Löthgren, M.; Tambour, M. Bootstrapping the DEA-based Malmquist Productivity Index. Appl. Econ. 1999, 31, 417-425. [CrossRef]

82. Simar, L.; Wilson, P.W. Statistical inference in nonparametric frontier models: The state of the art. J. Product. Anal. 2000, 13, 49-78. [CrossRef]

83. Aly, H.Y.; Grabowski, R.; Pasurka, C.; Rangan, N. Technical, Scale, and Allocative Efficiencies in U.S. Banking: An Empirical Investigation. Rev. Econ. Stat. 1990, 72, 211-218. [CrossRef]

84. Li, Y. DEA Efficiency Measurement with Undesirable Outputs: An Application to Taiwan's Commercial Banks. Int. J. Serv. Technol. Manag. 2005, 6, 544-555. [CrossRef]

85. Li, Y.; Chen, Y.K.; Chien, F.S.; Lee, W.C.; Hsu, Y.C. Study of Optimal Capital Adequacy Ratios. J. Product. Anal. 2016, 45, 261-274. [CrossRef]

86. Wackerly, D.D.; Mendenhall, W., III; Scheaffer, R.L. Mathematical Statistics with Applications, 7th ed.; Duxbury Press: Pacific Grove, CA, USA, 2008.

87. Amin, G.R.; Emrouznejad, A.; Rezaei, S. Some Clarifications on the DEA Clustering Approach. Eur. J. Oper. Res. 2011, 215, 498-501. [CrossRef]

88. Dai, X.; Kuosmanen, T. Best-Practice Benchmarking Using Clustering Methods: Application to Energy Regulation. Omega 2014, 42, 179-188. [CrossRef]

89. Li, Y. Analyzing Efficiencies of City Commercial Banks in China: An Application of the Bootstrapped DEA Approach. Pac-Basin Financ. J. 2020, 62, 101372. [CrossRef]

90. Kaufman, L.; Rousseeuw, P.J. Finding Groups in Data: An Introduction to Cluster Analysis; Wiley: New York, NY, USA, 1990.

91. Hirschberg, J.G.; Lye, J.N. Clustering in a Data Envelopment Analysis Using Bootstrapped Efficiency Scores. In Department of Economics-Working Papers Series 800; The University of Melbourne: Melbourne, Australia, 2001. 